\title{
A link between the COVID-19 pandemic and Kawasaki-like multi-system inflammatory syndrome in children
}

\author{
Manal Fouad Elshamaa ${ }^{1, A-F}$ \\ ${ }^{1}$ Pediatrics Department, National Research Centre, Cairo, Egypt \\ A - Research concept and design, B - Collection and/or assembly of data, C - Data analysis and interpretation, \\ $D$ - Writing the article, $E$ - Critical revision of the article, $F$ - Final approval of article \\ Manal Fouad Elshamaa. A link between the COVID-1 pandemic and Kawasaki-like multi-system inflammatory syndrome in children. J Pre-Clin \\ Clin Res. 2020; 14(4): 151-155. doi: 10.26444/jpccr/130368
}

\begin{abstract}
Introduction. COVID-19 (coronavirus disease 2019) - the epidemic outbreak caused by coronavirus-severe acute respiratory syndrome coronavirus 2 (SARS-CoV-2) - is a global public health problem. Children are less affected and have a mild form of the illness. The association between SARS-CoV-2 disease, COVID-19 and late symptoms of vasculitis is often suspected, in particular in young asymptomatic patients, especially due to the post-viral immune response.

Objective. The aim of the review is to describe the characteristics of children and adolescents affected by the development of Kawasaki-like mult-system inflammatory syndrome (KD) (MIS-C), and assesses its possible temporal association with SARS-CoV-2 infection.

Brief description of the state of knowledge. A group of children who presented with KD-type MIS-C during the COVID-19 pandemic have been identified in the United Kingdom, the United States, and Italy. Some children were diagnosed with SARSCoV-2 infection by real-time polymerase chain reaction and IgG antibodies. SARS-CoV-2 infection and hyperinflammation in COVID-19 can serve as an 'initial trigger' for KD. IVIG should be administered within seven days of onset of illness until KD symptoms disappear and COVID-19 test is negative. Large numbers of children in African countries with the SARS-CoV-2 epidemic are likely to be affected by KD, and in such cases, a shortage of IVIG supplies is expected.

Conclusions. This article suggests a correlation between COVID-19 and Kawasaki-like MIS-C, which is important for the care of sick children. However, the definitive relationship between childhood KD and COVID-19 needs to be confirmed by a large cohort study on a large numbers of infant and children patients worldwide.
\end{abstract}

\section{Key words}

COVID-19 pandemic, SARS-CoV-2, Kawasaki-like multi-system inflammatory syndrome, children

\section{INTRODUCTION}

The rapid spread of corona virus disease 2019 (COVID-19), due to the severe respiratory syndrome corona virus 2 , has created a global epidemic with infected people of all ages living in almost every country in the world. COVID-19 is a global health emergency which first appeared in December 2019, caused by a new type of coronavirus-severe acute respiratory syndrome coronavirus 2 (SARS-CoV-2). By 5 May 52020 , COVID-19 had been discovered in over 3.6 million people worldwide, although the medical burden of the pandemic was less in infected children. The paediatric population appears to be affected at a much lower rate than the adults population, with only $2 \%$ of cases reported in patients under 20 years of age $[1,2]$. In children and adolescents, infection with SARS$\mathrm{CoV}-2$ is the leading cause of symptoms of mild respiratory deficiency, while the severe forms are reported in adults $[3,4]$. The focus on children's vulnerabilities are for two reasons: 1 ) the extent to which children can transmit COVID-19; this is the key to a country being able to re-establish its community after a shutdown; 2) new disease, such as severe Kawasaki disease (KD) or multiple systemic inflammatory syndrome in children (MIS-C) are of concern to North American and European countries

Address for correspondence: Manal Fouad Elshamaa, 33 Elbohous street, Dokki, Cairo, Egypt, postal code,12311, Pediatrics Department,National Research Centre E-mail: manal_elshmaa@hotmail.com

Received:16.09.2020; accepted: 11.11.2020; first published: 02.12.2020

\section{OBJECTIVES}

The aim of this review is to discuss the symptoms in children and adolescents suffering from an outbreak of a Kawasakilike multi-system inflammatory syndrome, and to assess a possible correlation with the SARS-CoV-2 infection in order to provide an update on this relationship.

\section{DESCRIPTION OF THE STATE OF KNOWLEDGE}

Pathogenesis of COVID-19 in children. SARS-CoV-2 has a significant genetic similarity (approximately $80 \%$ ) to the causative agent of the severe acute respiratory syndrome (SARS) epidemic in 2002 - the severe acute respiratory syndrome corona virus (SARS- CoV) [5-7]. The surface of SARS-CoV-2 contains a spike protein that allows it to bind and target human cells. The SARS-CoV-2 receptor is an angiotensin converting enzyme 2 (ACE2) that is expressed mainly on the renal proximal tubular cells, epithelial cells, endothelial cells, and enterocytes. After attaching to ACE2, SARS-CoV-2 endocytoses inside the cell and attaches to a talllike receptor (TLRs) in the endosome. This interacting form stimulates an interferon type 1 (IFN) response, and enhances the expression of other pro-inflammatory cytokines via the nuclear factor $\mathrm{kB}$ (NF-B) [8-10].

Two major immune responses have been reported against SARS-CoV-2: an initial innate IFN immune response which 
has been described previously, and a secondary immune response that causes a cytokine storm. The first IFN response is targetted to effectively include and eliminate the virus, and the initial IFN peak appears to be important for the efficient control of the virus [11]. The constancy of IFN activity produced during an innate immune reaction is necessary for the recovery of the patient [12]. When macrophages are activated by IFN- $\alpha / \beta$ receptors after the initial IFN response, they release pro-inflammatory cytokines and chemo-attractants [13].

The other response to SARS-CoV-2 is that the antigenpresenting cells transform the spike protein antigens into T lymphocytes, leading to B lymphocytes activation and anti-spike immunoglobulins production. The coated SARS$\mathrm{CoV}-2$ enters the macrophages via Fc receptors when these immunoglobulins bind to the spike proteins [14 A cytokine storm occurs in the adaptive phase when these macrophages release pro-inflammatory cytokines $[14,15]$.

COVID-19 cell/tissue damage can occur in two ways: 1) direct damage of SARS-CoV-2 by viral replication; 2) the cytokine storm which causes deleterious effects of excessive immune response [16]. Studies in mice and non-human primates have shown that an immune response that is a disproportionate immune response to the virus greater than the virus titer was associated with death in SARS-CoV infection [17, 18]. Most people with infectious disease are mildly infected, although virus can lead to a serious illness primarily diagnosed as a respiratory distress syndrome (ARDS) with increased cytokines that lead to death [19]. Cytokine storm caused by unrestricted immune response leads to multi-organ disease due to hyperinflammation [20]. Although the entire world is more likely to be infected with SARS-CoV-2, this virus, however, infects certain groups of people with more serious illness. The elderly, smokers, and those with chronic illnesses, such as diabetes and high blood pressure, are the main risk groups [21-23].

At present, the exact cause a mild illness in children infected with SARS-CoV-2 remains obscure. Many agents could share in this mild response in children; however, the specific effects of these agents have not yet been studied:

1) children travel less than adults which could be a protective factor [24];

2) in childhood, smoking is not a problem and children's airways have a lower risk of air pollution than adults [24];

3) common chronic illness of adulthood, such as hypertension or type 2 diabetes mellitus, are not common in children [10];

4) the large number of microorganisms that colonize the upper respiratory tract of children can compete with SARS-CoV-2 [25-27];

5) the innate immune reaction is more powerful in children, although the adaptive immune system is less developed and less mature than in adults $[10,28]$. This can lead to a significant removal of the virus and the reduction of an exaggerated adaptive reaction;

6) the patterns of ACE2 expression in children may differ from those in adults [29].

A link between kawasaki-like MIS-C in children and the COVID-19 pandemic. In Italy, the United Kingdom and United States over the last few months, there has been an obvious group of children symptomized by with a KDlike illness, (https://time.com/5832461/ Kawasaki-disease-
COVID-19/). Blood parameters overlap in the reported cases while showing symptoms compatible with in COVID-19 in children. SARS CoV-2 infection has also been confirmed in some paediatric patients by using real-time polymerase chain reaction (RT-PCR) and IgG antibodies

Although the relationship of KD to COVID- 19 has not yet been elucidated, the inflammatory syndrome linked with SARS-Co-2 infection is of growing concern due to corona virus infection, and the possible link with KD affecting young children. According to this hypothesis, the case of a 6-month-old infant presented with classic KD and tested positive in COVID- 19 has been described in a recent study. The infant was treated with the recommended regimen of intravenous immunoglobulins (IVIG) and aspirin, which relieved the clinical symptoms [30]. An cohort study of COVID-19 in the Italian province of Bergamo also reported severe KD [31]. These studies have strengthened the possible association between COVID-19 and KD and broadened our conception of the two diseases in paediatrics.

$\mathrm{KD}$, an early childhood acute fever, is a systemic vasculitis which affects mainly the medium and small-sized arteries [32] with a special predilection for the coronary arteries. It was first introduced in the 1960s by the Japanese paediatrician, Dr Tomisaku Kawasaki. The highest incidence of KD is in Japan where more than 300/100,000 children $\leq 4$ years old are affected annually by the disease, compared to $25 / 100,000$ children $\leq 5$ years in North America [33,34]. Sporadic cases of atypical Kawasaki disease had been reported in Egypt $[35,36]$.

Although the cause of KD remains uncertain, unknown infectious agents (referred to as ' $\mathrm{X}$ ' pathogens) might be the primary cause. The role of a viral trigger has been suggested in some children with a genetic predisposition, as several studies have linked multiple viral agents to KD [37-39], including seasonal coronaviruses $[40,41]$, but not all studies concur $[42,43]$.

A classic diagnosis of KD requires at least five days of fever and the occurrence of four of the following (if the fever is found with $<4$ of the following, the presence of an Echoproven coronary artery disease could confirm the diagnosis of the disease, together with the exclusion of other similar diseases [44]:

1) changes in the extremities, e.g, oedema, erythema, and desquamation. This limits motion and prevents the children from lifting weights;

2) desquamation of the fingers and toes is usually seen 1-2 weeks after the onset of fever, begins primarily in the periungual region, then can affect the palms and soles;

3) bilateral non-exudative conjunctivitis;

4) non-vesicular polymorphous rash;

5) unilateral cervical lymphadenopathy, $>1.5 \mathrm{~cm}$, the least common clinical feature, found in about $40 \%$ of patients; 6) oral cavity changes, e.g. fissured or swollen lips, pharyngeal erythema, dry strawberry tongue.

There is an increase in endothelial inflammation and injury /dysfunction, probably after SARS-CoV-2 infection through the endothelial ACE2, as suggested by recent observations of an increased accumulation of inflammatory cells in the endothelium. An exacerbation of the inflammatory response within the coronary lesions can be caused by a systemic inflammatory response to pneumonia, leading to endothelial dysfunction [45] and an acceleration in the development of 
KD. Thus, SARS-CoV-2 infection and hyper-inflammation as a consequence of this infection may act as the main 'triggers' leading to KD (Fig. 1).

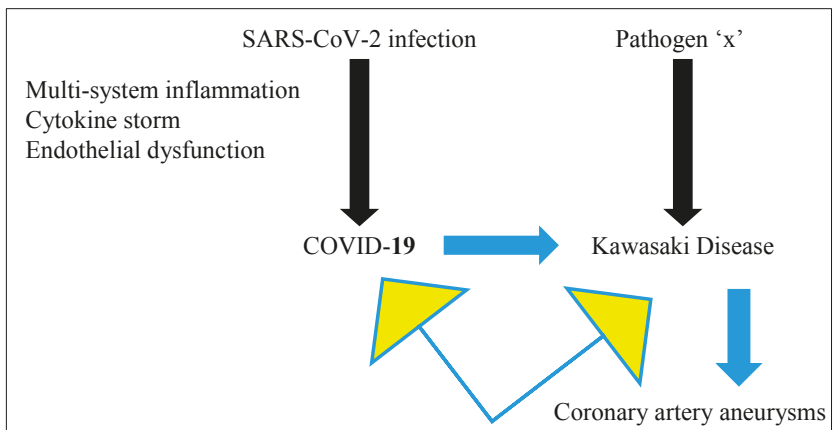

Intravenous immunoglobulin (Vasculitis) Anti-inflammatory agents (Aspirin, corticosteroids)

Figure 1. Probable association between COVID-19 and Kawasaki-like multi-system inflammatory syndrome

The World Health Organization (WHO) has developed an early case report form and a case definition for multisystem inflammatory diseases in children and adolescents. The definition of the initial case reflects the clinical and laboratory characteristics found in the previously reported children, and is used to identify suspected or confirmed cases for both treatment and preliminary reporting and follow-up.

Preliminary definition of cases. Children and adolescents aged $0-19$ years with fever $\geq 3$ days, and two of the following: 1) presence of a polymorphic rash or signs of mucocutaneous inflammation (mouth, hands, feet) or possibly nonsuppurative bilateral conjunctivitis;

2) pericarditis, valvitis, myocardial dysfunction or abnormalities of coronary artery (echo findings or increased levels of troponin/N-terminal (NT), pro-hormone B-type Natriuretic Peptide (NT-proBNP);

3) signs of shock or hypotension;

4) acute gastrointestinal disorders (diarrhea, vomiting, or abdominal pain). Additionally, increased erythrocyte sedimentation rate (ESR), C-reactive protein, procalcitonin, and other inflammatory markers;

5) coagulopathy parameters: prothrombin time (PT), partial thromboplastin time (PTT), increased D-dimer levels.

Additionally, there are no other clear microbial causes of inflammation, such as bacterial sepsis, staphylococcal or streptococcal shock syndrome. COVID-19 also evidences (antigen test, seropositive result or real-time PCR (RT-PCR) or probable communication with COVID-19 patients [46].

The presence of a positive SARS-CoV-2 test in KD patients elucidates the significance of COVID-19 testing in patients with KD. This is a valuable point, because most parents are reluctant to visit a hospital because of the executive order: 'stay-at-home' and the risk of catching an infection in the hospital [47]. Thus, KD may remain undiagnosed or incorrectly managed. Complete recovery usually occurs in most patients with KD after a few weeks. However, early management is needed to avoid the probable complications. Approximately 25\% of children with untreated KD develop coronary artery abnormalities, which are the main cause of short- and long- term morbidity and mortality. Myocardial infarction is the leading cause of mortality in KD. It can happen in the acute phase, but usually occurs during the first year from the first attack, but occurs later in patients with giant aneurysms [48].

Most KD patients respond well to IVIG treatment; however, an additional anti-inflammatory treatment (aspirin and corticosteroids) is required in $10-20 \%$ of patients [34]. These response variations raise the question of whether this group is a KD with SARS-CoV-2 which is the causative agent, or whether it demonstrates a new Kawasaki-like disease characterized by a multi-system inflammatory syndrome. Therefore, KD patients should be monitored carefully for possible CoVID-19 infections, and after IVIG infusion KD should be quarantined, or discharged if SARS KOV-2 test is positive. IVIG should be given within seven days of onset until symptoms of KD disappear and the COVID-19 test is negative.

Cardiac biopsy and scintigraphy have shown that mild myocarditis is common in the early stages of $\mathrm{KD}[49,27]$ and usually improves rapidly when the inflammation resolves [49-51]. However, in the case of KD shock syndrome, more severe myocarditis with decreased left ventricular contractility may occur. KD shock syndrome is more common in Western countries than in Asia; however, it is a rare complication affecting $1.5 \%-7.0 \%$ of patients with KD [52]. Myocardial dysfunction and decreased peripheral vascular resistance are the main causes of this syndrome, and is often treated in the intensive care unit by intravenous fluid resuscitation, vasoactive agent infusion and inotropic drugs $[53,54]$.

KD shock syndrome may mimic toxic shock syndrome [53], justifyingthe routine use of antibiotics in this setting. The pathophysiology of KD shock syndrome is still unknown. The presence of elevated levels of circulating pro-inflammatory cytokines may contribute to the distributive factor in the development of shock. KD shock syndrome has been shown to be accompanied with elevated levels of $\mathrm{C}$-reactive protein, procalcitonin, and IL-6 [52]. This major inflammatory condition associated with multiple organ failure, recently named Paediatric Multisystem Infammatory Syndrome (PIMS) [55], reflects a specifically potent post-viral immune response to SARS-CoV-2 in contrast to other viral agents [56]. In fact, in COVID-19 in adults, cytokine storm syndrome with increased IL6 levels as an inflammatory marker has been reported [57] and is accompanied with increased mortality [58]. Of note, KD shock syndrome was associated with old age, elevated levels of D-dimer, decreased levels of hemoglobin and albumin, and severe hyponatraemia [52].

In sub-Saharan Africa, KD is rarely reported, but may be more common than previously reported [59]. In the United Kingdom and the United States the incidence in children of Asian descent was 2.5 times higher than in children of European descent, with the average risk for children of African descent being 1.5 times higher $[60,61]$. In addition, Afro-Americans might show increased susceptibility to severe SARS-CoV-2 infection as they have been disproportionately affected by the COVID-19 epidemic [62, 63]. Thus, large numbers of children with KD may be exposed in African countries with generalized SARS-CoV-2 epidemics, and in such cases, a decrease in IVIG can be expected. In Asian countries, there are no reports of Kawasaki like-multisystem inflammatory syndrome associated with SARS- 
Co-2 infection. [1] Racial differences have been reported in previous cases of KD shock syndrome, with the incidence lower in Asian countries than in Western countries [49]. Therefore, more confirmatory studies are needed from a global perspective regarding the clinical properties of COVID-19 and the possible association between COVID-19 and KD.

While this article proposes a potential inflammatory syndrome linked with COVID-19, it is imperative for parents and healthcare providers to know that children are generally at minimal risk of SARS-CoV-2 infection. Recognition this inflammatory syndrome in children can provide important data about the immune reaction to SARS-CoV-2 and the potential correlation of immune defences that may be relevant for both children and adults. The reason for some children becoming seriously ill with COVID-19, while the majority do not show signs of the disease or are asymptomatic, may be explained by an antibody-mediated bas; vaccines studies might also be implicated

\section{CONCLUSION}

The link between Covid-19 and PIMS is therefore critical for the clinical care of ill children. The crucial association between Covid-19 and childhood KD still needs to be emphasized in a wide range of infants and children worldwide.

\section{Acknowledgment}

The author thanks the National Research Centre in Cairo, Egypt.

\section{Conflict of interest}

The author declares that there are no conflicts of interest.

\section{REFERENCES}

1.Lu X, Zhang L, Du H, et al. SARS-CoV-2 infection in children. N Engl J Med. 2020; 382(17): 1663-1665. https: //doi: 10.1056/NEJMc2005073. Epub 2020 Mar 18

2. Wu Z, McGoogan JM. Characteristics of and important lessons from the coronavirus disease 2019 (COVID-19) outbreak in China: summary of a report of 72314 cases from the Chinese Center for Disease Control and Prevention. JAMA. 2020; 323(13): 1239-1242. https: //doi:10.1001/ jama.2020.2648

3. Castagnoli R, Votto M, Licari A, et al. Severe Acute Respiratory Syndrome Coronavirus 2 (SARS-CoV-2) Infection in Children and Adolescents: A Systematic Review. JAMA Pediatr. Published online April 22, 2020. https: //doi: 10.1001/jamapediatrics.2020.1467

4. Dong Y, Mo X, Hu Y, et al. Epidemiology of COVID-19 among Children in China. Pediatric 2020: 145(6):e2020-0702. https: //doi:10.1542/ peds.2020-0702

5. Russell M Viner, Whittaker E. Kawasaki-like disease: emerging complication during the COVID-19 pandemic. Lancet. 2020; 395(10239): 1741-1743. https: //doi: 10.1016/S0140-6736(20)31129-6 [Epub ahead of print]

6. Lu R, Zhao X, Li, et al. Genomic characterisation and epidemiology of 2019 novel coronavirus: implications for virus origins and receptor binding. Lancet 2020; 395: 565-574. https: //doi.org/10.1016/S0140 $-6736(20) 30251-8$

7.Zhou P, Yang XL, Wang XG, et al. A pneumonia outbreak associated with a new coronavirus of probable bat origin. Nature 2020; 579: 270-273. https://doi.org/10.1038/s4158 6-020-2012-7

8. Chen J, Subbarao K. The Immunobiology of SARS*. Annu Rev Immunol. 2007; 25: 443-472. https://doi.org/10.1146/annur ev.immun ol.25.02210 6.141706
9. Du Toit A. Viral infection: changing sides to get in. Nat Rev Microbiol. 2016; 14: 476-477. https://doi.org/10.1038/nrmic ro.2016.98

10. Hedrich CM. COVID-19-considerations for the paediatric rheumatologist. Clin Immunol. 2020; 214: 108420. https://doi. org/10.1016/j.clim.2020.10842 0

11. Channappanavar R, Fehr AR, Vijay R, et al. Dysregulated type I interferon and inflammatory monocyte-macrophage responses cause lethal pneumonia in SARS-CoV-infected mice. Cell Host Microbe 2016; 19: 181-193. https://doi.org/10.1016/j.chom.2016.01.007

12. Cameron MJ, Ran L, Xu L, etal. Interferon-mediated immunopathological events are associated with atypical innate and adaptive immune responses in patients with severe acute respiratory syndrome. J Virol. 2007; 81: 8692-8706. https://doi. org/10.1128/JVI.00527-07

13. Ye Q, Wang B, Mao J. The pathogenesis and treatment of the 'Cytokine Storm' in COVID-19. J Infect. 2020; 80(6): 607-613. https://doi. org/10.1016/j.jinf.2020.03.037

14. Liu L, Wei Q, Lin Q, et al. Anti-spike IgG causes severe acute lung injury by skewing macrophage responses during acute SARS-CoV infection. JCI Insight. 2019; 4(4): e123158. https://doi.org/10.1172/jci. insig ht.12315 8

15. Fu Y, Cheng Y, Wu Y. Understanding SARS-CoV-2-mediated inflammatory responses: from mechanisms to potential therapeutic tools. Virol Sin. 2020; 35(3): 266-2711. https://doi.org/10.1007/s1225 0-02000207-4

16.Zhang W, Zhao Y, Zhang F, et al. The use of anti-inflammatory drugs in the treatment of people with severe coronavirus disease 2019 (COVID-19): the perspectives of clinical immunologists from China. Clin Immunol. 2020; 214: 108393. https:// doi.org/10.1016/j. clim.2020.108393

17. Rockx B, Baas T, Zornetzer GA, et al. Early upregulation of acute respiratory distress syndrome-associated cytokines promotes lethal disease in an aged-mouse model of severe acute respiratory syndrome coronavirus infection. J Virol. 2009; 83: 7062-7074. https://doi. org/10.1128/ JVI.00127-09

18. Smits SL, de Lang A, van den Brand JM, et al. Exacerbated innate host response to SARSCoV in aged non-human primates. PLoS Pathog.2010; 6(2):e1000756. https://doi.org/10.1371/journ al.ppat.10007 56

19. Misra DP, Agarwal V, Gasparyan AY, et al. Rheumatologists' perspective on coronavirus disease 19 (COVID-19) and potential therapeutic targets. Clin Rheumatol.2020; 39(7): 2055-2062. https://doi. org/10.1007/s1006 7-020-05073-9

20. Henderson LA, Canna SW, Schulert GS, et al. On the alert for cytokine storm: immunopathology in COVID-19. Arthritis Rheumatol. 2020; 72(7): 1059-1063. https://doi.org/10.1002/art.41285

21. Vardavas CI, Nikitara K. COVID-19 and smoking: a systematic review of the evidence. Tob Induc Dis. 2020; 18: 20. https://doi. org/10.18332 /tid/11932 4

22. Zhou F, Yu T, Du R, et al. Clinical course and risk factors for mortality of adult inpatients with COVID-19 in Wuhan, China: a retrospective cohort study. Lancet 2020; 395: 1054-1062. https://doi. org/10.1016/ S0140-6736(20)30566-3

23. Haslak F, Yildiz M, Adrovic A, et al. Childhood rheumatic diseases and COVID-19 pandemic: an intriguing linkage and a New Horizon. Balkan Med J. 2020; 37(4): 184-188. https:/doi.org/10.4274/balkanmedj. galenos.2020.2020.4.43

24. Lee PI, Hu YL, Chen PY, et al. Are children less susceptible to COVID-19? J Microbiol Immunol Infect. 2020; 53(3): 371-372. https:// doi.org/10.1016/j.jmii.2020.02.011

25. Brodin P. Why is COVID-19 so mild in children? Acta Paediatr. 2020; 109(6): 1082-1083. https://doi.org/10.1111/apa.15271

26. Liu Y, Yan LM, Wan L, et al. Viral dynamics in mild and severe cases of COVID-19. Lancet Infect Dis. 2020; 20(6): 656-657. https://doi. org/10.1016/S1473-3099(20)30232-2

27. Nickbakhsh S, Mair C, Matthews L, et al. Virus-virus interactions impact the population dynamics of influenza and the common cold. Proc Natl Acad Sci USA. 2019; 116(52): 27142-50. https://doi. org/10.1073/pnas.19110 83116

28. Carsetti R, Quintarelli C, Quinti I, et al. The immune system of children: the key to understanding SARS-CoV-2 susceptibility? The Lancet Child \& Adolescent Health. 2020; 4(6): 414-416. https://doi.org/10.1016/S23524642(20)30135-8

29. Chen J JQ, Xia X, Liu K, et al. Individual variation of the SARS-CoV2 receptor ACE2 gene expression and regulation. Aging Cell. 2020; 19(7): 10.1111/acel.13168. 19(7): 10.1111/acel.13168

30. Barsh GR, Maskatia S, Mathew R. COVID-19 and Kawasaki disease: novel virus and novel case, Hosp Pediatr. 2020; 10(6): 537-540. https:// doi.org/10.1542/hpeds.2020-0123 
31. Verdoni L, Mazza A, Gervasoni A, et al. An outbreak of severe Kawasakilike disease at the Italian epicentre of the SARS-CoV-2 epidemic: an observational cohort study, Lancet 2020; 395(10239): 1771-1778. https:// doi.org/10.1016/S0140-6736(20)31103-X

32. Schnabel A, Hedrich CM. Childhood Vasculitis. Front Pediatr 2019; 6: 421. https: //doi: 10.3389/fped.2018.00421

33. Makino N, Nakamura Y, Yashiro M, et al. Nationwide epidemiologic survey of Kawasaki disease in Japan, 2015-2016. Pediatr Int 2019; 61: 397-403. https: //doi:10.1111/ped.13809

34. McCrindle BW, Rowley AH, Newburger JW, et al, American Heart Association Rheumatic Fever, Endocarditis, and Kawasaki Disease Committee of the Council on Cardiovascular Disease in the Young; Council on Cardiovascular and Stroke Nursing; Council on Cardiovascular Surgery and Anesthesia; and Council on Epidemiology and Prevention. Diagnosis, Treatment, and Long-Term Management of Kawasaki Disease: A Scientific Statement for Health Professionals from the American Heart Association. Circulation 2017; 135: e927-99. https: //doi: 10.1161/CIR.0000000000000484

35. Hala M Agha and Hala S. Hamza Incomplete Kawasaki disease in Egypt Glob Cardiol Sci Pract. 2017; (3): e201724.1-5. https: //doi: 10.21542/ gcsp. 2017.24

36. Attia TH, Saeed MA and Fathalla D. Kawasaki Disease Presented with Meningitis in an Egyptian Adolescent Journal of Case Reports and Studies 2015 3(6)1-4. https: //doi: 10.15744/2348-9820.3.602

37. Turnier JL, Anderson MS, Heizer HR, et al. Concurrent Respiratory Viruses and Kawasaki Disease. Pediatrics 2015; 136: e609-14. https: // doi: 10.1542/peds.2015-0950

38. Catalano-Pons C, Quartier P, Leruez-Ville M, et al. Primary cytomegalovirus infection, atypical Kawasaki disease, and coronary aneurysms in 2 infants. Clin Infect Dis 2005; 41: e53-6. https: //doi: $10.1086 / 432578$

39. Bajolle F, Meritet JF, Rozenberg F, et al. Markers of a recent bocavirus infection in children with Kawasaki disease: "a year prospective study”. Pathol Biol (Paris) 2014; 62: 365-8. https: //doi:10.1016/j. patbio.2014.06.002

40. Esper F, Shapiro ED, Weibel C, et al. Association between a novel human coronavirus and Kawasaki disease. J Infect Dis. 2005; 191: 499-502. https: //doi:10.1086/428291

41. Chang LY, Lu CY, Shao PL, et al. Viral infections associated with Kawasaki disease. J Formos Med Assoc 2014; 113: 148-54. https://doi: 10.1016/j.jfma.2013.12.008

42. Lehmann C, Klar R, Lindner J, et al. Kawasaki disease lacks association with human coronavirus NL63 and human bocavirus. Pediatr Infect Dis J 2009; 28: 553-4. https://doi: 10.1097/ INF.0b013e31819f41b6

43. Kim JH, Yu JJ, Lee J, et al. Detection rate and clinical impact of respiratory viruses in children with Kawasaki disease. Korean J Pediatr 2012; 55: 470-3. https: //doi: 10.3345/kjp.2012.55.12.470

44. Rauch AM, Hurwitz ES. Centers for Disease Control [CDC] case definition for Kawasaki syndrome. Pediatr Infect Dis. 1985; 4: 702-703. https://doi: 10.1097/00006454-198511000-00029

45. Varga Z, Flammer A.J, Steiger P, et al. Endothelial cell infection and endotheliitis in COVID-19, Lancet 2020; 395(10234): 1417-1418. https: //doi: 10.1016/S0140-6736(20)30937-5

46. World Health Organization, 2020, May 15, Multisystem inflammatory syndrome in children and adolescents temporally related to COVID-19 Retrieved from https://www.who.int/news-room/commentaries/detail/ multisystem-inflammatory-syndrome-in-children-and-adolescentswith-covid-19. Health City, Texas: Author (Access 2020.6.20).
47. Harahsheh AS, Dahdah N, Newburger JW, et al. Missed or delayed diagnosis of Kawasaki disease during the 2019 novel coronavirus disease (COVID-19) pandemic, J Pediatr. 2020; 222: 261-262. https:// doi.org/10.1016/j.jpeds.2020.04.052.

48. Elshamaa MF. Kawasaki disease: The coronary affection perspective. Cardiothorac Vasc Sci. 2017; 1(1): 1-13. doi: 10.15761/CVS.1000105

49. Yutani C, Go S, Kamiya T, et al. Cardiac biopsy of Kawasaki disease. Arch Pathol Lab Med. 1981; 105: 470-3. PMID: 6895017

50. Kao $\mathrm{CH}$, Hsieh KS, Wang YL, et al. The detection of ventricular dysfunction and carditis in children with Kawasaki disease using equilibrium multigated blood pooling ventriculography and $99 \mathrm{Tcm}-$ HMPAO-labelled WBC heart scans. Nucl Med Commun 1993; 14: 539-43. https: //doi: 10.1097/00006231-199307000-00004

51.Harada M, Yokouchi Y, Oharaseki T, et al. Histopathological characteristics of myocarditis in acute-phase Kawasaki disease. Histopathology 2012; 61: 1156-67. https: //doi:10.1111/j.13652559.2012.04332.x

52.Li Y, Zheng Q, Zou L, et al. Kawasaki disease shock syndrome: clinical characteristics and possible use of IL- 6 , IL-10 and IFN- $\gamma$ as biomarkers for early recognition. Pediatr Rheumatol. 2019; 17(1): 1-9 https://doi: 10.1186/s12969-018-0303-4

53. Kanegaye JT, Wilder MS, Molkara D, et al. Recognition of a Kawasaki disease shock syndrome. Pediatrics 2009; 123: e783-9. https://doi: 10.1542/peds.2008-1871

54. Gatterre P, Oualha M, Dupic L, et al. Kawasaki disease: an unexpected etiology of shock and multiple organ dysfunction syndrome. Intensive Care Med. 2012; 38: 872-8. https://doi: 10.1007/s00134-012-2473-8

55. ECDC. Pediatric inflammatory multisystem syndrome and SARSCoV2infection in children, 2020. https://www.ecdc.europa.eu/ sites/default/ files/documents/covid-19-risk-assessment pediatric inflammatorymultisystem-syndrome-15-May-2020.pdf, (Access 2020.6.20).

56. Lee KY, Rhim JW, Kang JH. Kawasaki disease: laboratory findings and an immunopathogenesis on the premise of a "protein homeostasis system". Yonsei Med J. 2012; 53: 262-75. https://doi: 10.3349/ ymj.2012.53.2.262

57. Huang C, Wang Y, Li X, et al. Clinical features of patients infected with 2019 novel coronavirus in Wuhan, China. Lancet 2020; 395: 497-506. https://doi: 10.1016/S0140-6736(20)30183-5

58. Mehta P, McAuley DF, Brown M, et al. HLH across speciality collaboration, UK. COVID-19: consider cytokine storm syndromes and immunosuppression. Lancet 2020; 395: 1033-4. https://doi: 10.1016/ S0140-6736(20)30628-0

59. Noorani M, Lakhani N. Kawasaki disease: two case reports from the Aga Khan Hospital, Dar es Salaam-Tanzania. BMC Pediatr 2018; 18 : 334. https://doi: 10.1186/s12887-018-1306-5

60. Holman RC, Belay ED, Christensen KY, et al. Hospitalizations for Kawasaki syndrome among children in the United States, 19972007. Pediatr Infect Dis J 2010; 29: 483-8. https://doi: 10.1097/ INF.0b013e3181cf8705

61. Gardner-Medwin JM, Dolezalova P, Cummins C, et al. Incidence of Henoch-Schonlein purpura, Kawasaki disease, and rare vasculitides in children of different ethnic origins. Lancet 2002; 360: 1197-202. https: //doi:10.1016/S0140-6736(02)11279-7

62. Yancy CW. COVID-19 and African Americans. JAMA. 2020. https:// doi: 10.1001/jama.2020.6548

63. Giudicessi JR, Roden DM, Wilde AAM, et al. Genetic Susceptibility for COVID-19-Associated Sudden Cardiac Death in African Americans. Heart Rhythm 2020. S1547-527 1(20): 30419-7. https://oi: 10.1016/j. hrthm.2020.04.045 